\title{
EDUCATION, OCCUPATION AND OPERATIONAL MEASURES OF SARCOPENIA: SIX YEARS OF AUSTRALIAN DATA
}

*Sharon L Brennan-Olsen a,b,c BA(Hons), GCALL, PhD

(sharon.brennanolsen@deakin.edu.au)

Sara Vogrin a,b PhD (sara.vogrin@unimelb.edu.au)

Saliu Balogun ${ }^{d} \mathrm{PhD}$ (saliu.balogun@utas.edu.au)

Feitong Wu ${ }^{\text {d }} \mathrm{PhD}$ (feitong.wu@utas.edu.au)

David Scott a,b,e PhD (david.scott@monash.edu)

Graeme Jones d MD, MMedSc, MBBS (graeme.jones@utas.edu.au)

Alan Hayes a,b,f PhD (alan.hayes@vu.edu.au)

Steven Phu a,b BAppSc, GradDipExSc, MExSc (steven.phu@hotmail.com)

Gustavo Duque a,b MD, PhD, FRACP, FGSA (gustavo.duque@unimelb.edu.au)

Alison Beauchamp a,b,g PhD (Alison.beauchamp@monash.edu)

Jason Talevski a,b BHealthSci (jason.talevski@student.unimelb.edu.au)

Ghazala Naureen a,b MSc (gnaureen@student.unimelb.edu.au)

Tania M Winzenberg c PhD (tania.winzenberg@utas.edu.au)

a Department of Medicine-Western Health, The University of Melbourne, 176 Furlong Rd, St Albans, 3021, VIC, Aust.;

${ }^{b}$ Australian Institute for Musculoskeletal Science (AIMSS), The University of Melbourne and Western Health, 176 Furlong Rd, St Albans, 3021, VIC, Aust.;

c Deakin University, Geelong, Australia, School of Health and Social Development, Faculty of Health, Waterfront Campus, Gheringhap Street, Geelong, 3220, VIC, Aust.;

${ }^{d}$ Menzies Institute for Medical Research, University of Tasmania, 17 Liverpool St, Hobart, 7000, TAS, Aust.;

e School of Clinical Sciences at Monash Health, Monash University, 246 Clayton Rd, Clayton, 3168, VIC, Aust.

Institute of Health and Sport, Victoria University, Ballarat Rd, Footscray, 3011, VIC, Aust; ${ }^{g}$ School of Rural Health, Monash University, 15 Sargent St, Warragul, 3820, VIC, Aust.

\section{*CORRESPONDING AUTHOR:}

This is the author manuscript accepted for publication and has undergone full peer review but has not been through the copyediting, typesetting, pagination and proofreading process, which may lead to differences between this version and the Version of Record. Please cite this article as doi: $10.1111 /$ AJAG.12816

This article is protected by copyright. All rights reserved 
Professor Sharon L Brennan-Olsen

Deakin University, School of Health and Social Development, Faculty of Health

Waterfront Campus, 176 Furlong Road,

Geelong, VIC 3220, Australia

sharon.brennanolsen@deakin.edu.au Ph: +61 0352278362

MeSH Key Words: functional health status; economic status; epidemiology; health disparities

\section{CONFLICT OF INTEREST}

S.L.B-O. has received speaker fees from Amgen Australia and Pfizer Australia. D.S. has received speaker fees from Amgen Australia and consulting fees from Pfizer US. G.D. has received speaker fees from Amgen Australia, Eli Lilly, and Abbott, and consulting fees from Amgen Australia, Eli Lilly and Theramex.

\section{ACKNOWLEDGEMENTS}

This work was supported by the National Health and Medical Research Council (NHMRC) of Australia (Project Number 302204; Early Career Fellowship number 1158661 to F.W.; Career Development Fellowship number 1107510 to S.L.B-O., and number 1123014 to D.S.); Arthritis Foundation of Australia (MRI06161); Tasmanian Community Fund (D0015018); and University of Tasmania Institutional Research Grants Scheme (D0015019). S.L.B-O was also supported by a Research Fellowship from the Faculty of Medicine, Dentistry and Health Sciences, University of Melbourne. We gratefully acknowledge the efforts of the TasOAC participants and staff, particularly study coordinator Catrina Boon. We thank Darci Green, University of Melbourne, for her administrative support directly related to this manuscript.

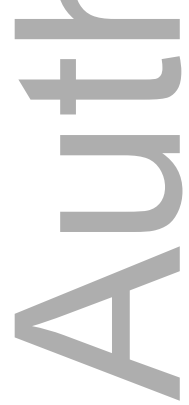

This article is protected by copyright. All rights reserved 


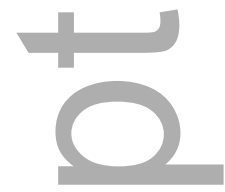

Article type

$$
\text { : Research Article }
$$

\title{
EDUCATION, OCCUPATION AND OPERATIONAL MEASURES OF SARCOPENIA: SIX YEARS OF AUSTRALIAN DATA
}

\begin{abstract}
:
Objectives: To examine associations of education and occupation with handgrip strength (HGS), lower limb strength (LLS), and appendicular lean mass (ALM).

Methods: Measures of HGS, LLS, and ALM (dual-energy X-ray absorptiometry) were ascertained at baseline in 1,090 adults (50-80yrs, 51\% women), 3yrs and 5yrs. Education and occupation were self-reported, the latter categorised as high-skilled white-collar (HSWC), low-skilled white-collar (LSWC), or blue-collar. Separate general estimating equations models were performed.
\end{abstract}

Results: The highest education group had greater HGS than the middle (0.33psi) and lowest (0.48psi) education groups, and $0.34 \mathrm{~kg}$ greater ALM than the lowest education group. HGS was 0.46psi greater for HSWC than LSWC groups. Compared to LSWC groups, LLS was $5.38 \mathrm{~kg}$ and $7.08 \mathrm{~kg}$ greater in HSWC and blue-collar groups. Blue-collar and HSWC groups each had $\sim 0.60-0.80 \mathrm{~kg}$ greater ALM than LSWC.

Conclusion: Progressive muscle loss can be prevented by targeted intervention thus we suggest clinical attention be directed toward specific social groups.

KEYWORDS: functional health status; economic status; epidemiology; health disparities

WORD COUNT: Manuscript: 3000, Abstract: 150 


\section{INTRODUCTION:}

The global population is ageing, yet, increased longevity does not always signify extra years lived in good health. Rather, some individuals appear to be living longer with declining physical capacities [1]. A healthy musculoskeletal system is an important determinant in the maintenance of functional capacity across the lifecourse. In 2016, sarcopenia was allocated an International Classification of Diseases, Tenth Revision, Clinical Modification (ICD-10CM) code (M62.84) [2]. Sarcopenia results in an increase in physical disability, falls, fractures, and mortality [3, 4]. Whilst an international consensus regarding the operational definition of sarcopenia is, as yet, non-existent $[3,5]$, the diagnostic criteria for sarcopenia include a combination of low muscle mass, strength and physical performance [6, 7]. Regardless of the definition applied and populations examined [5], sarcopenia prevalence is suggested to be approximately $30 \%$ [7].

The impact of socioeconomic status on sarcopenia prevalence is not well understood and it is not clear whether sarcopenia prevalence, like other disease, has a social gradient [8]. Yet, there are data suggesting such a gradient might exist. In a pooled study of 18,363 adults aged $\geq 65$ years from Finland, Poland, Spain, China, Ghana, India, Mexico and China, lower socioeconomic status (SES) was consistently associated with an increased risk of sarcopenia [9] defined by using indirect population equations to estimate skeletal muscle mass. However, much of the available literature has conflicting results from predominantly crosssectional data. For instance, cross-sectionally, lower educational attainment was associated with a greater likelihood of sarcopenia in 730 Italian community-dwelling adults aged $\geq 65$ years [10], but not in 70 Quilombola persons aged $\geq 60$ years from Brazil [11].

Lower household income and lower educational attainment may predispose populations to lower skilled occupations, which includes manual labour and repetitive exposures; however, lower functional capacity would increase the difficulty of performing job requirements with ease, and without injury. Should socially disadvantaged individuals be at a disproportionately greater risk of sarcopenia, this would also have significant implications for primary prevention, diagnosis and management. Indeed, the revised European Consensus regarding sarcopenia identified that, in clinical practice, low handgrip strength may be enough to trigger assessment, and potentially interventions, for sarcopenia [7], which is indicative of an 
increasing focus on muscle strength and function rather than muscle mass as a key determinant of sarcopenia [7, 12-14]. Given that a prompt identification of sarcopenia in clinical settings would be facilitated by ascertaining measures of operational sarcopenia quickly and cost-effectively [15], we aimed to examine associations between education and occupation with operational measures of sarcopenia (handgrip strength, lower limb strength, and appendicular lean mass [ALM]) across six years in a population-based sample of adults.

\section{METHODS:}

\section{Participants}

The Tasmanian Older Adult Cohort Study (TasOAC) is a prospective study of communitydwelling men and women resident in Southern Tasmania, Australia. Participants were randomly selected from the Commonwealth electoral rolls for southern Tasmania, with equal numbers of men to women (57\% participation). Phase 1 (baseline) measures for TasOAC were ascertained in 1,090 adults (51\% women; 50-80 years; 98\% Caucasian) from March 2002 to September 2004, Phase 2 measures were collected September 2004 to June 2007 ( $\mathrm{n}=873 ; 49 \%$ women), and Phase 3 measures were ascertained October 2007 to June 2009 ( $n=762 ; 50 \%$ women); notably, $70 \%$ of the sample had completed all visits. All participants in the TasOAC provided informed written consent. Approval for the study was obtained from the Southern Tasmania Health and Medical Human Research Ethics Committee (H1040).

\section{Operational measures of sarcopenia (commonly used in sarcopenia diagnoses)}

All measures were performed at each phase. Handgrip strength was measured by trained staff using a pneumatic dynamometer (psi) and lower limb strength was simultaneously measured in both legs to the nearest kilogram using a dynamometer (TTM Muscular Meter, Tokyo, Japan). An average of two measures for each was calculated. Participants underwent a wholebody scan, performed by a Hologic dual energy X-ray absorptiometry (DXA) scanner (Hologic Corp., Waltham, Massachusetts, USA), from which measures of appendicular lean mass (ALM; sum of lean mass in the arms and legs) were ascertained.

\section{Education, occupation, and area-level disadvantage}


The highest level of educational attainment self-reported at baseline was categorised in the three groups of having; (i) not completed secondary/high school, (ii) completed secondary/high school, or (iii) completed tertiary education.

The longest-held occupation, self-reported at baseline, was categorised using two different methods. First, we used the International Standard Classification of Occupations (ISCO-88) coding system to classify occupations according to the hierarchical dimensions of skill-level and specialisation [16]. Occupations were categorised into the ten major hierarchical groups, and further collapsed into four groups for analyses. Second, also based on the ISCO coding system, occupations were grouped into high-skilled white-collar (HSWC), low-skilled whitecollar (LSWC), or blue-collar groups, according to the classification standards employed by the European Foundation for the Improvement of Living and Working Conditions [17].

Area-level disadvantage was ascertained by matching the baseline residential address of each TasOAC participant to the corresponding Australian Bureau of Statistics (ABS) Census Collection District for 2001, after which ABS software was used to determine the SocioEconomic Indexes for Areas (SEIFA) value, as previously reported [18]. SEIFA is a collection of four separate indexes, derived from Australian Census data and constructed from different variables. The variables characterise subjects within an area, thereby providing a single measure to rank the level of disadvantage or advantage at the area level, not of the individual subject. The indexes are: Index of Relative Socioeconomic Disadvantage (IRSD), the Index of Relative Socioeconomic Advantage (IRSAD), the Index of Education and Occupation (IEO) and the Index of Economic Resources (IER). For these analyses we employed the IRSAD, which accounts for high and low area-based income and occupation types including unskilled employment to professional positions, among other variables. A low score as measured by the IRSAD represents a more disadvantaged area, while a high score represents a more advantaged area [19]. Participants were assigned to a category of social disadvantage according to quartile cut-points for SEIFA values were based on population values of the study region of Southern Tasmania, Australia [19].

\section{Anthropometrics, and lifestyle and behavioural exposures}

Weight, with shoes, socks and bulky clothing removed, was measured using a single pair of calibrated electronic scales (Seca Delta Model 707, Hamburg, Germany). Height, with shoes 
and socks removed, was measured by trained staff to the nearest $\pm 0.1 \mathrm{~cm}$ using a single calibrated stadiometer. Body mass index (BMI) was subsequently calculated as $\mathrm{kg} / \mathrm{m}^{2}$.

Self-reported lifestyle and behavioural exposures were obtained by questionnaire at the time of baseline DXA measures. Dietary protein intake (grams) was assessed using the selfreported Cancer Council of Victoria Food Frequency Questionnaire (CCV-FFQ) [20], which estimates intake over the previous 12 months from 101 food items. This validated tool includes both a frequency component and portion size of food items from which food intake is calculated as grams per day. For analyses, we investigated dietary protein intake as (i) a continuous measure, and (ii) consuming at least 1.2 grams per $\mathrm{kg}$ of body weight per day [21, 22]. Smoking was defined as current at the time of DXA measures, or as any lifetime history of smoking. A lifetime history of stroke and/or diabetes was ascertained by self-report, as was the incidence of hip fracture or major osteoporotic fracture (at the skeletal site of hip, wrist or spine), or having sustained an incident fracture at any skeletal site.

\section{Statistical analyses}

Descriptive characteristics were calculated and presented as mean and standard deviation $( \pm \mathrm{SD})$ (continuous variables) or frequency and percentage (categorical variables). The association of education and occupation on handgrip strength, lower limb strength, ALM ( $\mathrm{kg})$, ALM divided by BMI $\left(\mathrm{kg}\left[\mathrm{kg} / \mathrm{m}^{2}\right]\right)\left(\mathrm{ALM}_{\mathrm{BMI}}\right)$, and ALM divided by height squared $\left(\mathrm{kg} / \mathrm{m}^{2}\right)\left(\mathrm{ALM} / \mathrm{height}^{2}\right)$ were evaluated using general estimating equations separately for each exposure and outcome. The following confounders were considered and evaluated for inclusion in final models: age, sex, weight (except for ALM models), height, BMI, IRSAD quartiles, smoking (ever or current), dietary protein intake (continuous, and consuming above recommended dietary intake of $1.2 \mathrm{~g} / \mathrm{kg} /$ day), a history of stroke and $/$ or diabetes, and incident hip fractures, major osteoporotic fractures (hip, wrist, or spine), or fractures occurring at any skeletal site. The effect of each exposure on the change in the outcome was tested (entered as an interaction with time). Significance was set at $\mathrm{p}<0.05$, and all statistical analyses were performed using Stata (StataCorp, Release 15, College Station, TX).

\section{RESULTS:}


Table 1 presents descriptive characteristics of the study population at baseline and each of the follow-up Phases. Mean age at baseline was $63.0 \pm 7.5$ years. Mean handgrip strength ranged between 10-12 psi across the three timepoints, mean lower limb strength ranged between 91.4-96.5kg, and mean ALM ranged between $23.5-24.8 \mathrm{~kg}$. The greatest proportions of this study population had completed a tertiary education (46.9\%), held a HS white-collar occupation (42.9\%), were a manager/professional/technician $(49.7 \%)$, and lived in the most advantaged quartile of area-level SES (60.0\%) (all proportions shown are at Phase 3).

\section{Education and operational measures of sarcopenia}

Table 2 presents the best fitting model for associations between education groups and the outcomes of handgrip strength, lower limb strength, ALM, ALMBMI, and ALM/height ${ }^{2}$. After adjustment for age, sex, and height, those with a tertiary degree had $4.1 \%(0.48 \mathrm{psi}, 95 \% \mathrm{CI}$ 0.20-0.76) greater handgrip strength compared to those that had not completed secondary or high school, and $0.33 \mathrm{psi}$ (95\%CI 0.01-0.65) greater handgrip strength compared to those that had completed secondary or high school. For ALM, and after adjustment for age, sex and height, those with a tertiary degree had $1.4 \%$ greater lean mass than those that had not completed secondary/high school $(0.34 \mathrm{~kg}, 95 \% \mathrm{CI}$ 0.01-0.67). In those who completed tertiary education, $\mathrm{ALM}_{\mathrm{BMI}}$ was $3.3 \%\left(0.03 \mathrm{~kg} /\left(\mathrm{kg} / \mathrm{m}^{2}\right), 95 \%\right.$ CI $\left.0.01-0.04\right)$ higher than those who had not completed secondary school, after adjusting for sex and baseline current smoking. In sex-adjusted models, those who completed tertiary education had $0.13 \mathrm{~kg}$ (95\%CI $0.01,0.25$ ) higher ALM/height ${ }^{2}$ compared to those that had not completed secondary school. There were no interactions between education and time for any outcome. No further differences were observed.

\section{Occupation and operational measures of sarcopenia}

Table 3 presents the best fitting models for associations between occupation groups of HSWC, LSWC, and blue-collar and the outcomes of handgrip strength, lower limb strength, ALM, ALM $\mathrm{BMI}$, and ALM/height ${ }^{2}$. After adjustment was made for significant confounders of sex, weight, height and IRSAD, those working in a HSWC occupation had 4\% (0.46 psi, 95\% CI 0.15-0.78) greater handgrip strength compared to those working in LSWC occupations. No differences in handgrip strength were observed across hierarchical ISCO-defined occupation groups [16] (data not shown). After adjustment for significant confounders of sex, 
weight and height, those in the HSWC or blue-collar groups had 5.38kg (95\%CI 1.17-9.58) and $7.08 \mathrm{~kg}$ (95\%CI 1.69-12.49) greater leg strength compared to those in the LSWC group (7.7\% greater), respectively. After adjustment for sex, height, IRSAD, and any lifetime history of smoking, HSWC and blue-collar workers both had greater ALM compared to LSWC workers $(0.56 \mathrm{~kg}, 95 \% \mathrm{CI} 0.21-0.92$, and $0.79 \mathrm{~kg}$, 95\%CI $0.34-1.24$, respectively). In models adjusted for sex and any prior fracture, HSWC and blue-collar workers also had greater ALM/height2 compared to LSWC workers $(0.20 \mathrm{~kg}$, 95\%CI $0.07-0.034$, and $0.35 \mathrm{~kg}$, 95\% CI 0.18-0.53, respectively). No differences were observed for any measures of ALM across hierarchical ISCO-defined occupation groups [16], and IRSAD was not a significant confounder in any models (data not shown). There were no interactions between occupation and time for any outcome.

\section{DISCUSSION:}

Ours is the first study to investigate the association between social factors and operational measures of sarcopenia across multiple follow ups, in which measures of muscle mass were ascertained reproducibly from DXA. We report that, independent of age and other covariates, those with greater educational attainment were more likely to have stronger handgrip and more muscle mass. Holding a HSWC occupation was associated with a stronger handgrip, more muscle mass and greater leg strength than holding a LSWC occupation, and those with blue-collar jobs had more muscle mass and greater leg strength that their LSWC counterparts. The magnitude of $\sim 8 \%$ difference in leg strength observed between occupation groups could be functionally and clinically important. The effect of SES-related variables did not vary over time thus no cumulative effect was observed; however, that we observed some clinically and functionally important differences in LLS, and some smaller differences in HGS and ALM, between social groups suggests that sarcopenia could be added to the list of diseases affected by social factors, and thus add impetus to the need to address the social determinants of health. As such, these results indicate that those who have not completed secondary/high school, or who are involved in LSWC occupations, may potentially have greater risk for sarcopenia onset, and/or those holding blue-collar occupations may potentially be protected due to the physical activity needs of their work.

There are few studies with which we can compare our findings regarding educational attainment and operational measures of sarcopenia, however, we report similar associations 
with ALM to those observed in a Swedish study of 185 participants with type 2 diabetes [23]. In order to compare our findings against other studies, we may also consider the inextricable link between education and income, whereby higher educational attainment is associated with increased capacity for income. In this context, a study of 2,091 adults from Baltimore, USA, in which the sampling frame for recruitment crossed age, sex, race (African American and Caucasian) and SES [24], reported a positive association between income and handgrip strength, however it was only observed for men, and not women [24].

In our study, holding a HSWC and blue-collar occupations were both beneficially associated with all sarcopenia measures except ALM/height ${ }^{2}$ and HGS (for blue-collar occupations), with largest effect sizes seen in the blue-collar group. Our findings aligned with those of the Hertfordshire Cohort Study, in which no evidence was found for an association between physically demanding occupations and handgrip strength in 1,418 adult men who had worked for at least 20 years [25]. For ALM, our findings differed from those observed in the Korea National Health and Nutrition Examination Survey [26]. In that study of 679 Korean men, in which a calculated skeletal muscle mass index (SMMI) was employed to determine sarcopenia, the highest mean SMMI was observed for men with a lifetime occupation in agribusiness, fishing or low-level laborers compared to those in white-, blue- or pink-collar occupations (the latter group was similar to, although not fully aligned with, our LSWC definition). Given that we grouped all manual occupations into the blue-collar group, it is likely that our findings of greater ALM in the blue-collar group are comparable to the findings reported in Korean blue-collar group. However, we also observed greater ALM in the HSWC group, which was not seen in the Korean HSWC population. In context of a paucity of data in this field, lower SES across the lifetime has been associated with lower lean mass in women, and a contemporaneous association between household income and lean mass has been reported for men [27]. Whilst little is known about the role of social factors on lower limb strength, given the associations we observed with ALM, our findings are consistent.

Speculation exists as to why parameters of SES such as education and occupation may influence operational measures of sarcopenia. First, there are common familial and peerrelated environmental influences between higher education and measures of body habitus such as obesity [28], and thus plausibly ALM and related strength measures. In addition to the direct biological effects exerted on ALM by lifestyle factors, it is possible that, similar to 
bone health [29], inflammatory dysregulation may have considerable relevance for the field of sarcopenia. Psycho-social environments that are characterised by chronic stress, a situation well-documented as more common for those of lower SES, may result in a chronically heightened inflammatory state that places disadvantaged individuals at greater risk of muscle loss. However, although sensitivity to the social environment is supported by data pertaining to the link between neural, endocrine and immune function [30], there exist few data specifically investigating these complex relationships in sarcopenia.

While lean mass variables differed in several comparisons between education and occupation, muscle strength also differed for the same comparisons. This suggests that the low-cost and simple muscle strength tests may be sufficient to detect education- and occupation-related differences in sarcopenia status. Debate continues regarding the value of including DXAassessed lean mass in definitions of sarcopenia, with a bias toward agreement for muscle strength assessments being a key component.

Our study has some limitations. These data are from a community-dwelling and generally Caucasian population resident in Southern Tasmania, Australia, and thus we highlight that our findings may have limited generalisability for populations of other ethnicity or locations. Our population was biased toward having higher education, holding higher-skilled occupations, and residing in more advantaged areas; however, this may suggest that the differences we observed between social groups are conservative. Finally, given that our measures of handgrip strength, lower limb strength and ALM varied randomly across the three time-points, we cannot rule out that this may be partly explained by loss to follow up, which was somewhat higher in those with lower education, or held a LSWC, particularly between Phase 1 and 2. This study also has strengths. Ours is the first to investigate associations between social factors and operational measures of sarcopenia across multiple follow ups, in which measures of muscle mass were ascertained reproducibly from DXA. Furthermore, given the paucity of data in this field of enquiry, we provide further evidence for differences between educational and occupational groups in operational measures of sarcopenia.

\section{CONCLUSION:}


In the context of a scant literature base regarding whether a social gradient of sarcopenia exists, these data support the possibility of such a gradient. Considering the functional and clinical importance of the $\sim 8 \%$ difference in leg strength that we observed between occupation groups, we suggest sarcopenia should be added to the list of chronic diseases that are affected by social factors, adding impetus to calls to address social determinants of health. Given the emerging evidence that progressive muscle loss can be prevented by targeted intervention, our data will inform public health promotion and clinical attention toward those most at risk.

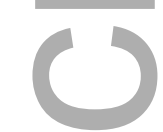

\section{Policy Impact Statement}

We observed a functionally important difference of $\sim 8 \%$ in leg strength between occupation groups. We suggest sarcopenia should be added to the list of chronic diseases that are affected by social factors, adding impetus to calls to address social determinants of health.

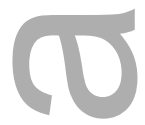

\section{Practice Impact Statement}

We observed a functionally and clinically important difference of $\sim 8 \%$ in leg strength between occupation groups, adding impetus to calls to address social determinants of health within clinical settings. Emerging evidence indicates that progressive muscle loss can be prevented by targeted intervention, thus directing clinical attention toward specific social groups.

\section{REFERENCES}

1. World Health Organization. World Report on Ageing and Health. World Health Organization, Geneva, Switzerland. 2015. http://www.who.int/ageing/events/world-report2015-launch/en/. Accessed April 7, 2019.

2. Anker SD, Morely JE, von Haehling S. Welcome to the ICD-10 code for sarcopenia. J Cachexia Sarcopenia Muscle. 2016;7(5):512-514. https://doi.org/10.1002/jcsm.12147.

3. Zanker J, Scott D, Reijnierse EM, et al. Establishing an operational definition of sarcopenia in Australia and New Zealand: Delphi method based consensus statement. J Nutr Health Aging. 2019;23(1):105-110. https://doi.org/10.1007/s12603-018-1113-6. 
4. Zhao Y, Zhang Y, Hao Q, Ge M, Dong B. Sarcopenia and hospital-related outcomes in the old people: A systematic review and meta-analysis. Aging Clin Exp Res. 2019;31(1):514. https://doi.org/10.1007/s40520-018-0931-z.

5. Reijnierse EM, Trappenburg MC, Leter MH, et al. The impact of different diagnostic criteria on the prevalence of sarcopenia in healthy elderly participants and geriatric outpatients. Gerontol. 2015;61(6):491-496. https://doi.org/10.1159/000377699.

6. Cruz-Jentoft AJ, Landi F, Schneider SM, et al. Prevalence of and interventions for sarcopenia in ageing adults: a systematic review. Report of the International Sarcopenia Initiative (EWGSOP and IWGS). Age Ageing, 2014;43(6):748-759. https://doi.org/10.1093/ageing.afu115.

7. Cruz-Jentoft AJ, Bahat G, Bauer J, et al. Sarcopenia: Revised European consensus on definition and diagnosis. Age Ageing. 2019;48(1):16-31. https://doi.org/10.1093/ageing/afy169.

8. Green D, Duque G, Fredman N, Rizvi A, Brennan-Olsen SL. Is there a social gradient of sarcopenia? A meta-analysis and systematic review protocol. BMJ Open. 2018;8:e019088. https://doi.org/10.1136/bmjopen-2017-019088.

9. Tyrovolas S, Koyanagi A, Olaya B, et al. Factors associated with skeletal muscle mass, sarcopenia, and sarcopenic obesity in older adults: a multi-continent study. J Cachexia Sarcopenia Muscle. 2016;7(3):312-321. https://doi.org/10.1002/jcsm.12076.

10. Volpato S, Bianchi L, Cherubini A, et al. Prevalence and clinical correlates of sarcopenia in community-dwelling older people: application of the EWGSOP definition and diagnostic algorithm. J Gerontol A Biol Sci Med Sci. 2014;69(4):438-446. https://doi.org/10.1093/gerona/glt149.

11. Neto LSS, Karnikowski MGO, Osorio NB, et al. Association between sarcopenia and quality of life in quilombola elderly in Brazil. Int J Gen Med. 2016;9:89-97. https://doi.org/10.2147/IJGM.S92404.

12. Schaap LA, van Schoor NM, Lips P, Visser M. Associations of sarcopenia definitions, and their components, with the incidence of recurrent falling and fractures: The Longitudinal Aging Study Amsterdan. J Gerontol A Biol Sci Med Sci. 2018;73(9):1199-1204. https://doi.org/10.1093/gerona/glx245.

13. Alley DE, Shardell MD, Peters KW, et al. Grip strength cutpoints for the identification of clinically relevant weakness. J Gerontol A Biol Sci Med Sci. 2014;69(5):559566. https://doi.org/10.1093/gerona/glu011. 
14. Castell M-V, Sanchez M, Julian R, Queipo R, Martin S, Otero A. Frailty prevalence and slow walking speed in persons age 65 and older: implications for primary care. BMC Family Practice. 2013;14(86). https://doi.org/10.1186/1471-2296-14-86.

15. Cesari M, Kritchevsky SB, Newman AB, et al. Added value of physical performance measures in predicting adverse health-related events: Results from the Health, Aging, and Body Composition Study. J Am Geriatr Soc. 2009;57(2):251-259. https://doi.org/10.1111/j.1532-5415.2008.02126.x.

16. International Labour Organization. International statistical comparisons of occupational and social structures: problems, possibilities and the role of ISCO-88. International Labour Organization, Geneva. 2004. http://www.ilo.org/global/statistics-anddatabases/WCMS_087941/lang--en/index.htm. Accessed April 10, 2019.

17. EuroFound. European Foundation for the Improvement of Living and Working Conditions: Coding and classification standards. Eurofound. 2010. https://www.eurofound.europa.eu/surveys/ewcs/2005/classification. Accessed 19th October 2018.

18. Brennan SL, Winzenberg TM, Pasco JA, Wluka AE, Dobbins AG, Jones G. Social disadvantage, bone mineral density and vertebral wedge deformities in the Tasmanian Older Adult Cohort. Osteoporos Int. 2013;24(6):1909-1916. https://doi.org/10.1007/s00198-0122211-7.

19. Australian Bureau of Statistics. Census of Population and Housing: Socio-Economic Indexes for Areas; Australia 2001 Number 2039.0. ABS, Canberra. 2001. http://www.https://www.ausstats.abs.gov.au/Ausstats/free.nsf/Lookup/AFF5E8542B58B94E CA256DD5007A3DF8/\$File/20390_2001.pdf. Accessed April 10, 2019.

20. Ireland P, Jolley D, Giles G, et al. Development of the Melbourne FFQ: A food frequency questionnaire for use in an Australian prospective study involving an ethnically diverse cohort. Asia Pacific J Clin Nutr. 1994;3(1):19-31. https://ncbi.nlm.gov/pubmed/24351203.

21. Paddon-Jones D, Short KR, Campbell WW, Volpi E, Wolfe RR. Role of dietary protein in the sarcopenia of aging. Amer J Clin Nutr. 2008;87(5):15625-15665. https://doi.org/10.1093/ajcn/87.5.1562S.

22. Paddon-Jones D, Campbell WW, Jacques PF, et al. Protein and healthy aging. Am J Clin Nutr. 2015;101(6):1339S-1345S. https://doi.org/10.3945/ajcn.114.084061. 
23. Allet L, Giet O, Barral J, et al. Educational level is related to physical fitness in patients with type 2 diabetes - a cross-sectional study. PLOS One. 2016;11(10):e0164176. https://doi.org/10.1371/journal.pone.0164176.

24. Thorpe RJ, Simonsick E, Zondeman A, Evans MK. Association between race, household income and grip strength in middle- and older-aged adults. Ethn Dis. 2016;26(4):493-500. https://doi.org/10.18865/ed.26.4.493.

25. Walker-Bone K, D'Angelo S, Syddall HE, et al. Heavy manual work throughout the working lifetime and muscle strength among men at retirement age. Occup Environ Med. 2016;73(4):284-286. https://doi.org/10.1136/oemed-2015-103293.

26. Kim SH, Kim W, Tang S, Kwon S, Choi KH. Influence of occupation on sarcopenia, sarcopenia obesity, and metabolic syndrome in men over 65 years of age. J Occupational Environ Med. 2018;60(10):e512-e517. https://doi.org/10.1097/JOM.0000000000001412. 27. Bann D, Cooper R. Wills AK, et al. Socioeconomic position across life and body composition in early old age: findings from a British birth cohort study. J Epidemiol Comm Health. 2014;68(6):516-523. http://dx.doi.org/10.1136/jech-2013-203373.

28. Johnson W, Kyvik KO, Skytthe A, Deary IJ, Sorensen TIA. Education modifies genetic and environmental influences on BMI. PLOS One. 2011;6(1):e16290. https://doi.org/10.1371/journal.pone.0016290.

29. Brennan-Olsen SL, Page RS, Berk M, et al. DNA methylation and the social gradient of osteoporotic fracture: A conceptual model. Bone. 2016;84(March):204-212. https://doi.org/10.1016/j.bone.2015.12.015.

30. Irwin MR, Cole SW. Reciprocal regulation of the neural and innate immune systems. Nat Rev Immunol. 2011;11(9):625-632. https://doi.org/10.1038/nri3042.

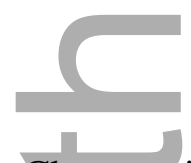

Table 1: Characteristics of the study population at baseline (Phase 1) and each follow up Phase, presented as mean ( \pm standard deviation $[\mathrm{SD}])$, or $\mathrm{n}(\%)$.

\begin{tabular}{lccc}
\hline Characteristic & Phase 1, n=1,090 & Phase 2, n=873 & Phase 3, n=762 \\
\cline { 2 - 4 } Age (years) & $63.0( \pm 7.5)$ & $65.2( \pm 7.3)$ & $67.1( \pm 7.0)$ \\
Women & $558(51.2 \%)$ & $430(49.3 \%)$ & $380(49.9 \%)$ \\
Handgrip strength (psi) & $12.0( \pm 3.0)$ & $10.0( \pm 3.0)$ & $11.3( \pm 4.3)$ \\
Lower limb strength (kg) & $92.5( \pm 48.9)$ & $96.4( \pm 50.3)$ & $91.0( \pm 49.9)$ \\
Appendicular Lean Mass (ALM) (kg) & $24.4( \pm 5.3)$ & $23.5( \pm 5.0)$ & $24.8( \pm 5.3)$ \\
\hline
\end{tabular}




\begin{tabular}{|c|c|c|c|}
\hline $\operatorname{ALM}_{\text {BMI }}\left(\mathrm{kg} /\left[\mathrm{kg} / \mathrm{m}^{2}\right]\right)$ & $0.9( \pm 0.2)$ & $0.9( \pm 0.2)$ & $0.9( \pm 0.2)$ \\
\hline ALM/height ${ }^{2}\left(\mathrm{~kg} / \mathrm{m}^{2}\right)$ & $8.7( \pm 1.3)$ & $8.3( \pm 1.2)$ & $8.9( \pm 1.3)$ \\
\hline \multicolumn{4}{|l|}{ Baseline education } \\
\hline Not completed secondary/high school & $396(36.3 \%)$ & $293(33.6 \%)$ & $250(32.8 \%)$ \\
\hline Completed secondary/high school & $220(20.2 \%)$ & $176(20.2 \%)$ & $155(20.3 \%)$ \\
\hline Completed tertiary education & $474(43.5 \%)$ & $404(46.3 \%)$ & $357(46.9 \%)$ \\
\hline \multicolumn{4}{|l|}{ Baseline collar occupation groups } \\
\hline High-skilled white-collar & $430(39.4 \%)$ & $369(42.3 \%)$ & $327(42.9 \%)$ \\
\hline Low-skilled white-collar & $401(36.8 \%)$ & $304(34.8 \%)$ & $264(34.6 \%)$ \\
\hline Blue-collar & $251(23.0 \%)$ & $194(22.2 \%)$ & $166(21.8 \%)$ \\
\hline Armed forces & $8(0.7 \%)$ & $6(0.7 \%)$ & $5(0.7 \%)$ \\
\hline \multicolumn{4}{|l|}{ Baseline Hierarchical occupation groups } \\
\hline Managers/professionals/technicians & $518(47.5)$ & $430(49.3)$ & $379(49.7)$ \\
\hline Clerical/services/agricultural & $379(34.8)$ & $295(33.8)$ & $257(33.7)$ \\
\hline Craft/machine operators/elementary & $152(13.9)$ & $118(13.5)$ & $102(13.4)$ \\
\hline Armed Forces & $41(3.8)$ & $30(3.4)$ & $24(3.1)$ \\
\hline \multicolumn{4}{|l|}{ Anthropometric measures } \\
\hline Height $(\mathrm{cm})$ & $166.9( \pm 9.0)$ & $167.0( \pm 9.0)$ & $166.6( \pm 9.0)$ \\
\hline Weight (kg) & $77.7( \pm 14.7)$ & $78.1( \pm 14.8)$ & $78.1( \pm 14.8)$ \\
\hline Body Mass Index $\left(\mathrm{kg} / \mathrm{m}^{2}\right)$ & $27.8( \pm 4.6)$ & $28.0( \pm 4.8)$ & $28.1( \pm 4.8)$ \\
\hline \multicolumn{4}{|l|}{ Lifestyle exposures } \\
\hline Currently smoking & $129(11.8 \%)$ & $91(10.4 \%)$ & $71(9.3 \%)$ \\
\hline Any lifetime history of smoking & $550(50.5 \%)$ & $429(49.1 \%)$ & $373(49.0 \%)$ \\
\hline Protein intake $(\mathrm{gm})$ & $87.2( \pm 36.0)$ & $86.9( \pm 33.2)$ & $86.3( \pm 36.3)$ \\
\hline Protein intake $(>1.2 \mathrm{~g} / \mathrm{kg} / \mathrm{day})^{\mathrm{b}}$ & $389(35.7 \%)$ & $313(35.9 \%)$ & $252(33.1 \%)$ \\
\hline \multicolumn{4}{|l|}{ History of specific comorbid conditions } \\
\hline Prevalent stroke and/or diabetes & $70(6.4 \%)$ & $71(8.1 \%)$ & $73(9.6 \%)$ \\
\hline Incident hip fracture & c & $5(0.6 \%)$ & $1(0.1 \%)$ \\
\hline Incident major osteoporotic fracture ${ }^{\mathrm{d}}$ & c & $21(2.4 \%)$ & $20(2.6 \%)$ \\
\hline Incident fracture at any skeletal site & c & $53(6.1 \%)$ & $51(6.7 \%)$ \\
\hline \multicolumn{4}{|l|}{ Baseline IRSAD quartiles } \\
\hline Quartile 1 (most disadvantaged) & $86(7.9 \%)$ & $63(7.2 \%)$ & $53(7.0 \%)$ \\
\hline Quartile 2 & $146(13.4 \%)$ & $112(12.8 \%)$ & $96(12.6 \%)$ \\
\hline
\end{tabular}




\begin{tabular}{llll}
\hline Quartile 3 & $233(21.4 \%)$ & $183(21.0 \%)$ & $156(20.5 \%)$ \\
Quartile 4 (most advantaged) & $625(57.3 \%)$ & $515(59.0 \%)$ & $457(60.0 \%)$ \\
\hline
\end{tabular}

Note. IRSAD=Index of Relative Socioeconomic Advantage and Disadvantage; a missing data:

Phase $1, n=44$, Phase 2, $n=46$, Phase $3, n=57 ;{ }^{b}$ met recommended intake of 1.2 grams per $\mathrm{kg}$ of body weight per day; ${ }^{\mathrm{c}}$ data not collected; ${ }^{\mathrm{d}}$ includes hip, wrist or spine.

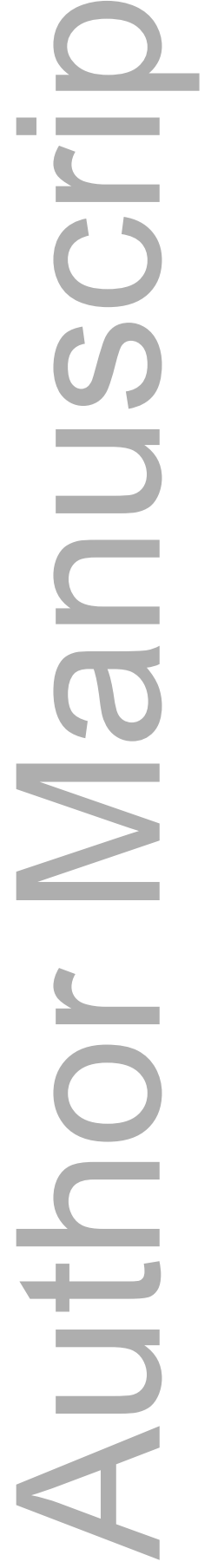


Table 2: Multivariable (best) models showing the mean difference and 95\% confidence intervals (95\%CI), with $\mathrm{p}$ value, between education groups and the outcomes of handgrip strength, lower limb strength, ALM, ALM ${ }_{B M I}$, and ALM/height ${ }^{2}$

\begin{tabular}{|c|c|c|c|c|c|c|}
\hline \multirow[b]{2}{*}{ Outcome (confounders adjusted for) } & \multicolumn{2}{|c|}{$\begin{array}{l}\text { Completed vs not completed } \\
\text { secondary/high school }^{\text {a }}\end{array}$} & \multicolumn{2}{|c|}{$\begin{array}{l}\text { Tertiary vs not completed } \\
\text { secondary/high school }^{\text {a }}\end{array}$} & \multicolumn{2}{|c|}{$\begin{array}{l}\text { Tertiary vs completed } \\
\text { secondary/high school }^{\text {a }}\end{array}$} \\
\hline & $\begin{array}{l}\text { Mean difference } \\
\qquad(95 \% \mathrm{CI})\end{array}$ & $\mathrm{p}$ & $\begin{array}{l}\text { Mean difference } \\
\qquad(95 \% \mathrm{CI})\end{array}$ & $\mathrm{p}$ & $\begin{array}{l}\text { Mean difference } \\
\qquad(95 \% \mathrm{CI})\end{array}$ & $\mathrm{p}$ \\
\hline \multicolumn{7}{|l|}{ Handgrip strength (psi) } \\
\hline (Age, sex, height) & $0.15(-0.18,0.48)$ & 0.36 & $0.48(0.20,0.76)$ & 0.001 & $0.33(0.01,0.65)$ & 0.04 \\
\hline \multicolumn{7}{|l|}{ Lower limb strength (kg) } \\
\hline (Age, sex, weight, height) & $2.78(-1.91,7.47)$ & 0.25 & $1.76(-2.11,5.63)$ & 0.37 & $-1.03(-5.78,3.72)$ & 0.67 \\
\hline \multicolumn{7}{|l|}{$\operatorname{ALM}(\mathrm{kg}) \bigcirc$} \\
\hline (Age, sex, height) & $0.03(-0.36,0.43)$ & 0.88 & $0.34(0.01,0.67)$ & 0.04 & $0.31(-0.08,0.70)$ & 0.12 \\
\hline \multicolumn{7}{|l|}{ ALM } \\
\hline (Sex, current smoking at baseline) & $0.02(-0.01,0.04)$ & 0.06 & $0.03(0.01,0.04)$ & 0.001 & $0.01(-0.01,0.03)$ & 0.33 \\
\hline \multicolumn{7}{|l|}{ ALM/height ${ }^{2}\left(\mathrm{~kg} / \mathrm{m}^{2}\right)$} \\
\hline$(\operatorname{Sex})$ & $0.00(-0.14,0.15)$ & 0.99 & $0.13(0.01,0.25)$ & 0.04 & $0.13(-0.01,0.27)$ & 0.08 \\
\hline
\end{tabular}

Note. Bolded data indicates statistical significance; ALM=appendicular lean mass; BMI=body mass index; ${ }^{\text {a }}$ Referent group is italicised.

Table 3: Multivariable (best) models showing the mean difference and 95\% confidence intervals (95\%CI), with p value, between occupation groups and the outcomes of handgrip strength, lower limb strength, ALM, ALM ${ }_{\mathrm{BMI}}$, and ALM/height ${ }^{2}$

\begin{tabular}{lllllcr}
\hline & \multicolumn{2}{c}{ HSWC vs LSWC $^{\text {a }}$} & \multicolumn{2}{c}{ Blue-collar vs LSWC $^{\text {a }}$} & \multicolumn{2}{c}{ Blue-collar vs HSWC $^{\text {a }}$} \\
\cline { 2 - 6 } Outcome (confounders adjusted for) & Mean difference & p & Mean difference & p & Mean difference & p \\
\hline
\end{tabular}

This article is protected by copyright. All rights reserved 


\section{Handgrip strength (psi)}

(Sex, weight, height, IRSAD)

Lower limb strength (kg)

(Sex, weight, height)

ALM (kg)

(Sex, height, IRSAD, smoking ${ }^{\mathrm{b}}$ )

$0.46(0.15,0.78)$

0.004

$0.36(-0.06,0.77)$

0.10

$-0.11(-0.50,0.28)$

0.59

$5.38(1.17,9.58)$

0.01

$7.08(1.69,12.49)$

0.01

$1.71(-3.63,7.05)$

0.53

$\operatorname{ALM}_{\text {BMI }}\left(\mathrm{kg} /\left[\mathrm{kg} / \mathrm{m}^{2}\right]\right)$

(Sex)

(

$0.56(0.21,0.92)$

0.002

$0.79(0.34,1.24)$

0.001

$0.23(-0.19,0.64)$

0.28

$0.02(-0.00,0.03)$

0.05

$-0.02(-0.04,0.00)$

0.103

$-0.03(-0.05,-0.01)$

0.001

ALM/height ${ }^{2}\left(\mathrm{~kg} / \mathrm{m}^{2}\right)$

(Sex, any fracture ${ }^{c}$ )

$0.20(0.07,0.34)$

0.004

$0.35(0.18,0.53)$

$<0.001$

$0.15(-0.01,0.31)$

0.06

Note. Bolded data indicates statistical significance; ALM=appendicular lean mass; BMI=body mass index; HSWC=high-skilled white-collar; IRSAD=Index of Relative Socioeconomic Advantage and Disadvantage; LSWC=low-skilled white collar; ${ }^{a}$ Referent group is italicised; ${ }^{\mathrm{b}}$ any lifetime history of smoking; ${ }^{\mathrm{c}}$ incident fracture that occurred at any skeletal site.

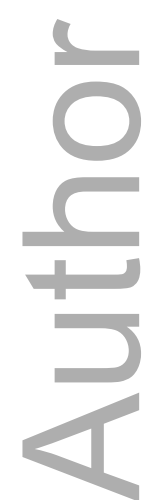

This article is protected by copyright. All rights reserved 


\section{University Library}

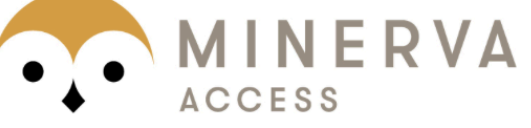

A gateway to Melbourne's research publications

Minerva Access is the Institutional Repository of The University of Melbourne

Author/s:

Brennan-Olsen, SL;Vogrin, S;Balogun, S;Wu, F;Scott, D;Jones, G;Hayes, A;Phu, S;Duque, G;Beauchamp, A;Talevski, J;Naureen, G;Winzenberg, TM

Title:

Education, occupation and operational measures of sarcopenia: Six years of australian data

Date:

2020-12

Citation:

Brennan-Olsen, S. L., Vogrin, S., Balogun, S., Wu, F., Scott, D., Jones, G., Hayes, A., Phu, S., Duque, G., Beauchamp, A., Talevski, J., Naureen, G. \& Winzenberg, T. M. (2020).

Education, occupation and operational measures of sarcopenia: Six years of australian data. AUSTRALASIAN JOURNAL ON AGEING, 39 (4), pp.E498-E505. https://doi.org/10.1111/ ajag. 12816.

Persistent Link:

http://hdl.handle.net/11343/276342 